\title{
ANALYSIS OF DEGRADATION OF ECOLOGICAL TRANSMISSION- HYDRAULIC FLUIDS USED IN AGRICULTURAL AND FORESTRY MACHINERY
}

\author{
Janoušková R. , Nosian J. ${ }^{* *}$, Feriancová P. ${ }^{* * *}$, Markiewicz M. ${ }^{* * * *}$
}

\begin{abstract}
In the scientific work we describe how ecological transmission-hydraulic fluid degrades during operation of agricultural and forestry machinery. We focused on investigating the physical-chemical properties of ecological transmission-hydraulic fluid. Measuring and sampling was performed under laboratory conditions, using a simulation device for testing transmission-hydraulic circuits in agricultural and forestry machinery.
\end{abstract}

\section{Keywords: Hydraulic system, Laboratory test, Ecological fluid, Hydraulic pump, Agricultural machinery.}

\section{Introduction}

Hydraulic fluid is energy carrier in agricultural technology (Hujo et al., 2019 and Hujo, Kangalov and Kosiba, 2015). These machines are used mostly on the fields; therefore, it is very important that the manufacturers produce fluids which are environmentally friendly (Tkáč, 2017). Nowadays, it is more and more difficult to produce oil of the required quality at an affordable price. Lubricant manufacturers are constantly striving to improve the quality of hydraulic fluid. Puškár, Brestovič and Jasminská (2015) and Puškár (2019) performed a comprehensive analysis of the effect of biodegradable fluids and mixtures thereof. The laboratory test equipment enables us to test the lifetime of service fluid undergoing temperature changes, operation pressures, flow changes and degradation of ecological transmission-hydraulic fluid. Additives are used to improve the properties of liquids (anti-corrosion, viscous-thermal, anti-aging protection, etc.) (Jablonický, 2012). Condition of the fluid is evaluated according to predetermined intervals or continuously. Accelerated testing is used to optimize time. One of the reasons for the analysis of fluids and lubricants is to ensure the smooth and reliable operation of machines and equipment (Čorñák, 2018 and Jablonický, 2014).

\section{Methods}

Fluid deforms continuously while in operation and is subjected to shear stress regardless of particle size (Kosiba, 2016). According to Kopiláková (2017), when conducting liquid tests, temperature and pressure affect the measurements. Fluid samples were subjected to following laboratory tests: ferro-graphic analysis, acid number measurement, particle number determination and classification. Pressure sensor (HAD 4748H-0400-000), temperature sensor (ETS 4148-H-006-000) and flow sensor (EVS 3108-H-0300-000) were used to measure the characteristics of transmission-hydraulic circuits. A recording unite HYDAC HMG 3010 was used to record the measured values (pressure, temperature, liquid flow) (Hujo, 2016).

\footnotetext{
Ing. Romana Janoušková: Faculty of Engineering, Slovak University of Agriculture; Tr. A. Hlinku 2; 949 76, Nitra; SK, xjanouskova@uniag.sk

** Ing. Jozef Nosian: Faculty of Engineering, Slovak University of Agriculture; Tr. A. Hlinku 2; 949 76, Nitra; SK, xnosian@uniag.sk

*** Ing. Patrícia Feriancová: Faculty of Engineering, Slovak University of Agriculture; Tr. A. Hlinku 2; 949 76, Nitra; SK, xferiancova@uniag.sk

**** Mgr. Inż. Marietta Markiewicz: Faculty of Mechanical Engineering, University of Science and Technology; ul. Kaliskiego 7, 85-789, Bydgoszcz; PL, marietta.markiewicz@utp.edu.pl
} 


\subsection{Ferro-graphic analysis}

Ferro-graphic analysis is a diagnostic method used to locate the wear point of the fluid based on the type of elements present in the operating fluid. We used this method to determine the amount and type of worn particles in the hydraulic system. We expect an increase in the number of particles in the oil samples during the tests. The reason for the increase is the gradual wear of friction components in the transmissionhydraulic elements. We use ferro-graph for ferro-graphic analysis Analytical Ferro-graph $\mathrm{T}^{2} \mathrm{FM}$. We proceed by mixing the fluid with perchlorethylene in a 2:1 ratio (we will achieve a better accentuation of wear particles). Set the ferro-graph to operating position and prepare a clean glass under which is a magnet for trapping metal particles. Sample is poured into a glass flask on a ferro-graph. The drip process takes around 10-15 minutes. Impurities are trapped under the fluid film on a ferro-graphic glass. Afterwards, it is necessary to clean the ferro-graph. This is done by pouring about $1 \mathrm{dcl}$ of technical gasoline into the upper bank of the ferro-graph. We switch on the device and after start-up the device starts to drip technical gasoline. After the cleaning process is done, we let the glass from the ferro-graph dry out. The last phase is the examination of the sample under the microscope KAPA 6000.

\subsection{Acid number}

Wear of fluid fillings is conditioned by oxidation of hydrocarbons, which creates substances with acidic character. Acid number determines the amount of these substances, which are determined by potentiometric titration using a FluidScan Q1000. Construction of the analyzer is based on an optical system firmly coupled to the specific spectral band used for the analysis of fluid (acid number TAN - TotalAcidNumber).

\subsection{Particle counting and classification}

We use LNF (LaserNetFines) laser particle counting technology to analyze hydraulic and lubricating fluids in the field of tribotechnic, as well as to determine the number of particles and their classification (Kučera, 2013). Using this technology, we obtain information about the state of hydraulic fluid and technical condition of the device. It can identify particles up to size $100 \mu \mathrm{m}$. We need a minimum of $5-15 \mathrm{ml}$ of fluid to measure.

\section{Results}

Based on the aforementioned methods, we took measurements and obtained the necessary data for the analysis of ecological transmission-hydraulic fluids.

\subsection{Analysis of ferro-graphy}

The analysis was performed with the oil samples after 125, 250, 375 and 500 hours worked in a laboratory test facility. Fig. 1 shows ferro-graphs taken at 400 times magnification using a KAPA 600. Analysis was carried out using the TRICO particle atlas. Figures show optical micrographs of sliding wear particles from the surface of friction couples. Using the atlas to compare, we found that wear occurred in the friction nodes of the generator due to the load at the operating temperature of $90-96{ }^{\circ} \mathrm{C}$, rotation increase $2350-2400 \mathrm{rpm}$. The shear mixed layer became unstable on the surface of the friction couple, chipping off of the particles, causing an increased level of wear. If the stress increases, the entire surface may break and the wear rate may be unbearable.
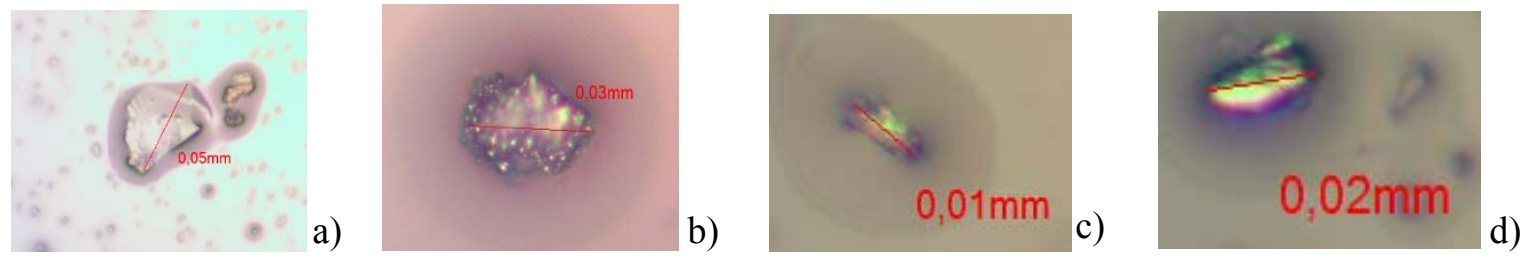

Fig. 1: Wear particles in fluid samples: a) 125 hours worked; b) 250 hours worked; c) 375 hours worked; d) 500 hours worked.

\subsection{Acid number analysis ISO 15380:2016}

Based on the ISO standard, the acid number is determined to increase by TAN $=2 \operatorname{mgKOH} . \mathrm{g}^{-1}$. Tab. 1 shows the dependence of the acid number of the TAN and the limit value with respect to the number of 
hours worked. After 500 hours of work, the acid value increased from $1.56 \mathrm{mgKOH} . \mathrm{g}^{-1}$ to $1.6 \mathrm{mgKOH} . \mathrm{g}^{-1}$ (a total increase of $2.6 \%$ ). On the basis of ISO, the acid number limit value is $3.56 \mathrm{mgKOH} . \mathrm{g}^{-1}$ and thus the acid number of the ecological transmission-hydraulic fluid did not exceed the limited value.

Tab. 1: The dependence of the acid number of the TAN and the limit value on relation to the number of hours worked.

\begin{tabular}{|c|c|c|c|c|c|}
\hline Hours worked & $\mathbf{0}$ & 125 & 250 & 375 & 500 \\
\hline TAN (mgKOH.g $\left.g^{-1}\right)$ & 1.56 & 1.34 & 1.43 & 1.7 & 1.6 \\
\hline Limit value $\left(\mathrm{mgKOH} . \mathrm{g}^{-1}\right)$ & 3.56 & 3.56 & 3.56 & 3.56 & 3.56 \\
\hline
\end{tabular}

\subsection{Analysis of wear particles by laser LNF-C}

Using a fluid sample at 0 hours worked, the cutting particles had a value of $25.2 \mu \mathrm{m}$. After 500 hours worked, the number of particles increased to $33.2 \mu \mathrm{m}$, which represents an increase $\Delta \mathrm{A}=31.7 \%$. The sliding parts at 0 hours worked had a value of $24.9 \mu \mathrm{m}$. After 500 hours worked, the number of particles increased to $27.2 \mu \mathrm{m}$, which represents an increase $\Delta \mathrm{A}=9.2 \%$. The fatigue particles at 0 hours worked had a value of $25.7 \mu \mathrm{m}$. After 500 hours worked, the number of particles increase to $31.5 \mu \mathrm{m}$, which represents an increase $\Delta \mathrm{A}=22.6 \%$. The nonmetallic particles at 0 hours worked had a value $31.8 \mu \mathrm{m}$. After 500 hours worked, the number of particles increase to $37 \mu \mathrm{m}$, which represent an increase $\Delta \mathrm{A}=16.4 \%$.

Fig. 2 shows particle samples using the LNF, where the shape of cutting (a), sliding (b), fatigue (c) and nonmetallic (d) particles can be observed. Then we compare the given particle shape with samples of ecological transmission-hydraulic fluid.
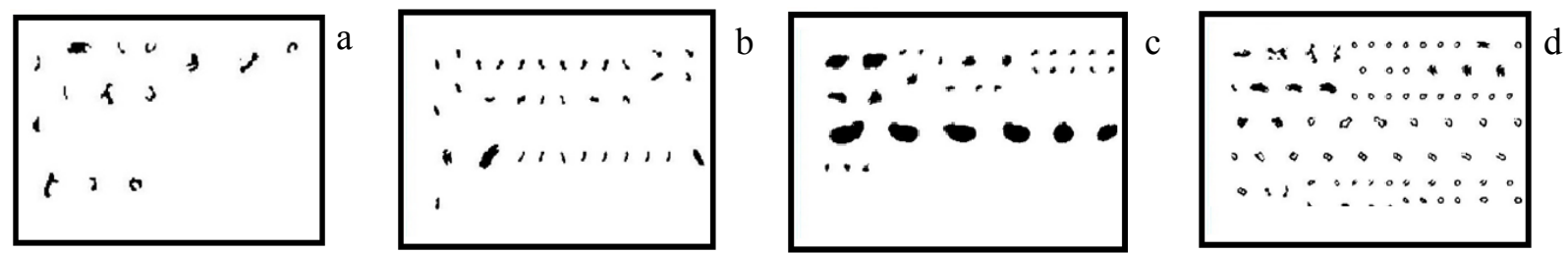

Fig. 2: Particles in the LNF analyzer.

Fig. 3 is a graphical representation of the number of particles per $1 \mathrm{ml}$ compared to the abrasive particle size defined by ISO 4406:2017. The dependence shows that the highest number of abrasive particles per $1 \mathrm{ml}$ of fluid with value 76749 is $>4 \mu \mathrm{m}, 18713$ is $>6 \mu \mathrm{m}$ a 688 is $>14 \mu \mathrm{m}$.

Fig. 4 is a graphical comparison of ISO 4406:2017 wear in terms of hours worked. For particles $>4 \mu \mathrm{m}$ from the sample at 0 hours worked with number of wear particles 76740 , we observe a decrease after 125 hours worked to a level with a particle number of 3286 , representing a decrease of $\Delta \mathrm{A}=95.7 \%$. For particles $>6 \mu \mathrm{m}$ from the sample at 0 hours worked with number of wear particles 18713 , we observe a decrease after 125 hours worked a level with a particle number of 1113 , representing a decrease of $\Delta \mathrm{A}=94 \%$. For particles $>14 \mu \mathrm{m}$ from the sample at 0 hours worked with number of wear particles 688 , we observe a decrease after 125 hours worked to a level with a particle number of 87 , representing

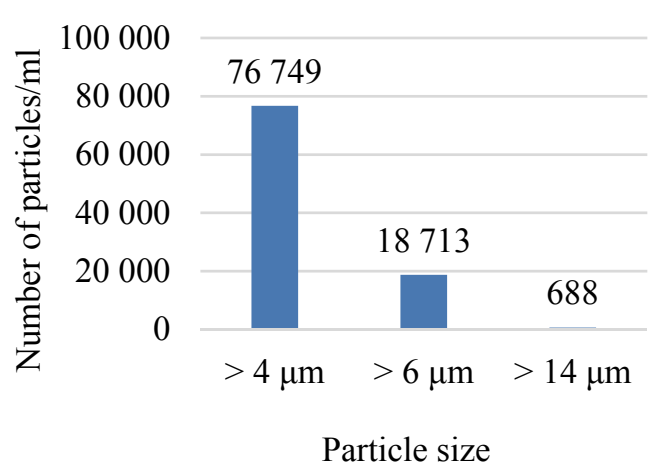

Fig. 3: ISO 4406:2017 wear comparison at 0 worked hours.

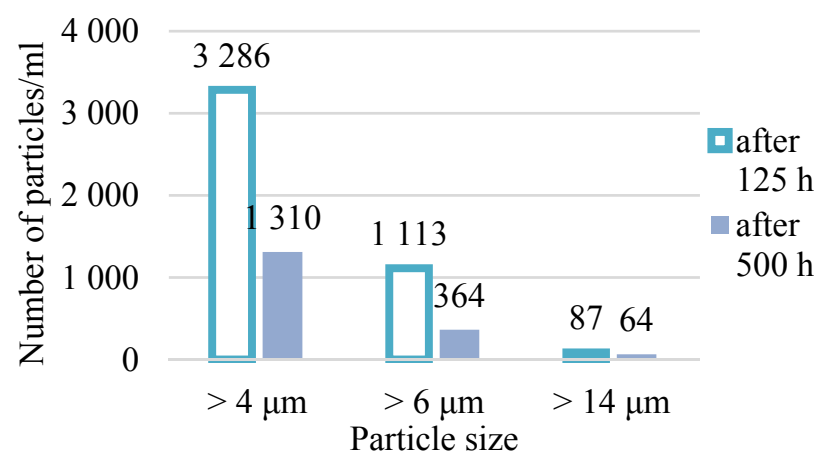

Fig. 4: ISO 4406:201 wear comparison with worked hours. 
a decrease of $\Delta \mathrm{A}=87.3 \%$. The decrease in the number of abrasive particles according to ISO at 0 hours worked and 125 hours worked is explained by the large number of air bubbles and fibers that were activated after hours worked and were not detected in the subsequent LNF fluid test. Likewise, in Fig. 4 we can see a decrease on the number of particles after 500 hours worked.

\section{Conclusion}

Ecological transmission-hydraulic fluid requires high purity and lack of water (Tulík, 2017). As it has been already proven during the measuring, when the machine is working, dirt is always present, whether it arises during work or accidentally gets into the system e. g., water. Therefore, precise production is required, which places difficult requirements on the production of components for hydraulic circuits using CNC machines, where the production accuracy is monitored using new methods (multi-criteria diagnostics of CNC machines) (Košinár and Kuric, 2011 and Kuric, Zajačko and Cisár, 2016). According to Kosiba (2013), the reason for the increase in worn-out particles is the wear of the filter.

\section{Acknowledgement}

This work was supported by project VEGA 1/0155/18 „Applied research of the use of ecological energy carriers in agricultural, forestry and transport technology“. This work was supported by project KEGA 028SPU-4/2019 „Practical utilization of design and testing knowledge of transmission systems of hydraulic mechanisms of mobile agricultural and forestry machinery." This work was supported by project APVV SK-PL-18-0041 „The Development of Scientific Cooperation in the Study of the Effects of Biofuels in Road Transport, Including Environmental Impact."

\section{References}

Čornák, Š. (2018) Identification of operating fluids with fingerprint method utilization. In $17^{\text {th }}$ Inter. Conf. Engineering for Rural Development. Jelgava, Latvia, 23-25 May. Jelgava: Latvia University of Agriculture, pp. 2048-2053.

Hujo, L. et al. (2019) Laboratory research of transmission - hydraulic fluid. In $7^{\text {th }}$ Inter. Conf. on Trends in Agricultural Engineering. Prague, CZ, 17-20 Sept. Prague: Czech University of Life Science Prague, pp. 183-188.

Hujo, L., Kangalov, P, and Kosiba J. (2015) Laboratory test devices for evaluating the lifetime of tractor hydraulic components: (proceedings, methods and applications). $1^{\text {st }}$ ed., Ruse: University of Ruse "Angel Kanchev".

Hujo, L. et al. (2016) Monitoring of operation loading of three-point linkage during ploughing. Research in Agricultural Engineering, 62(1): 24-29.

Jablonický, J. et al. (2014) Comparing the hydraulic control of tractor three-point hitch. Acta Universitatis Agriculturae et Silviculturae Mendelianae Brunensis 62 (5): 939-944.

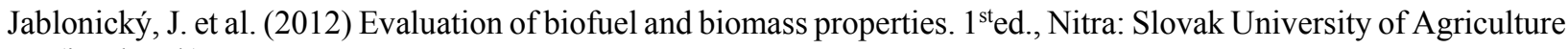
(in Slovak).

Kopiláková, B. et al. (2017) Evaluation of hydraulic resistance in various liquids and temperature. Tribology in Industry, 39(1): 129-135.

Kosiba, J. et al. (2016) Monitoring oil degradation during operating tests. Agronomy Research, 14(5): 1626-1634.

Kosiba, J. et al. (2013) The operation of agricultural tractor with universal ecological oil. Research in Agricultural Engineering, 59(2013): 27-33.

Kučera, M. et al. (2013) Possibility of hydraulic fluids with a low environmental impact application in agriculture and transport machinery. Journal of Central European Agriculture, 14(4): 1592-1601.

Košinár, M. and Kuric, I. (2011) Monitoring of CNC machine tool accuracy. Postepy nauki i techniki, 6(2011): 145-154.

Kuric, I., Zajačko, I. and Císar M. (2016) Analytical Intelligence tools for multicriterial of CNC machines. Advances in Science and Technology Research Journal, 10(32): 59-64.

Puškár, M., Brestovič, T. and Jasminská N. (2015) Numerical simulation and experimental analysis of acoustic wave influences on brake mean effective pressure in thrust-ejector inlet pipe of combustion engine. International Journal of Vehicle Design, 67(1): 63-67.

Puškár, M. et al. (2019) Complex analysis of influence of biodiesel and its mixture on regulated and unregulated emissions of motor vehicles with the aim to protect air quality and environment. Air Quality, Atmosphere \& Health, 12(7): 855-864.

Tkáč, Z. et al. (2017) Research of biodegradable fluid impacts on operation of tractor hydraulic system. Acta Technologica Agriculturae, 20(2): 42-45.

Tulík, J. et al. (2017) Evaluation of new biodegradable fluid on the basis of accelerated durability test, FTIR and ICP spectroscopy. Research in Agricultural Engineering, 63(1): 1-9. 